\title{
On the Contribution of the Geodetic Institute Potsdam to the International Latitude Service
}

\author{
Joachim Höpfner \\ GeoForschungsZentrum Potsdam, Division: Kinematics and Dynamics \\ of the Earth, Telegrafenberg A17, D-14473 Potsdam, Germany; e-mail: \\ ho@gfz-potsdam.de
}

\begin{abstract}
The paper reviews in what ways the Geodetic Institute Potsdam contributed to the foundation of the International Latitude Service (ILS) and took part in its activities through the work of Helmert, Albrecht, Wanach and Mahnkopf. Based on international scientific cooperation, the results were the rectangular coordinates of the polar motion from 1890.0 to 1922.7 at 0.1 year intervals, in particular those derived from the latitude observations at independent stations from 1890.0 to 1899.8 , and those derived from the latitude observations at the ILS stations from 1899.9 to 1922.7 .
\end{abstract}

\section{Introduction}

The history of the study of polar motion began with the derivation of the equations for the rotation of a rigid body by Euler published in 1758. This was followed by further theoretical contributions made by Lagrange (1788) and Poinsot (1834). To confirm the existence of the polar motion of the Earth in terms of a variation of latitude, intensive efforts were undertaken at several observatories toward the end of the 19 th century.

\section{Period between 1883 and 1899}

Oct. 1883 7th General Conference of the European Arc Measurement in Rome: Fergola suggested to investigate the problem using simultaneous latitude observations.

1888 Küstner detected a variation in latitude observations made at the Berlin Observatory.

Sept. 1888 Annual Conference of the Permanent Commission of the Internationale Erdmessung in Salzburg: Foerster proposed to consider the variation of latitude more systematically by a Special Commission.

1889 The Berlin, Potsdam, Prague and Strasbourg observatories started their cooperation to observe latitude variations. 

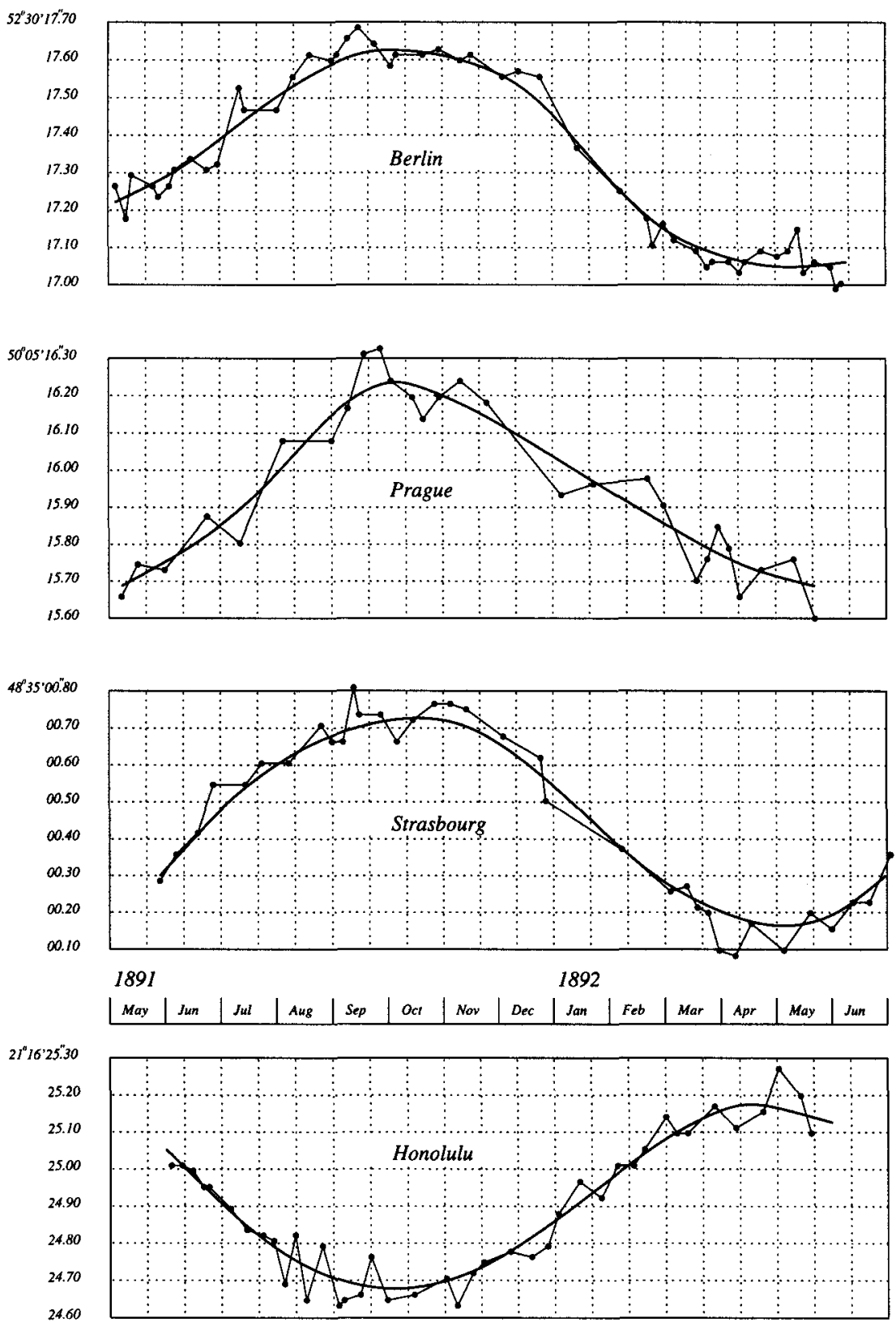

Figure 1. Comparison of the simultaneous latitude variations observed at Berlin, Prague, Strasbourg and Honolulu from May 1891 to June 1892 (from Albrecht, 1892). The mean values are denoted by filled circles. 
Oct. 1889 9th General Conference of the Internationale Erdmessung in Paris: Helmert reported on the cooperation of several observatories with the objective of studying small motions of the Earth's axis.

Oct. 1891 Annual Conference of the Permanent Commission of the Internationale Erdmessung in Florence: Helmert reported that an expedition to Honolulu was prepared and that Marcuse began to observe on June 1, 1891.

Sept. 1892 10th General Conference of the Internationale Erdmessung in Brussels: Helmert reported on the results in studying the latitude variation using the observations at Berlin, Prague, Strasbourg and Honolulu; see Figure 1.

After longer discussion of a plan submitted by the Special Commission, the proposal was adopted. From this, the following points should be noted:

- It is confirmed that significant periodic variations of the rotation axis exist.

- The Permanent Commission should continue its efforts.

- The Central Bureau continues to organize the latitude observations and to derive and publish the results.

- All steps should result in establishing and maintaining some observation stations on the same parallel.

Sept. 1895 11th General Conference of the Internationale Erdmessung in Berlin: The contractual base of the Erdmessung was renewed. The new convention decided that the annual budget will increase to 60000 Marks.

A new Special Commission was appointed with the task to work out a detailed program of the latitude service including the cost.

Oct. 1896 Annual Conference of the Permanent Commission of the Internationale Erdmessung in Lausanne: Albrecht presented the following three papers:

(1) On the status in studying the latitude variation including the polar motion; see Figure 2.

(2) On the choice of the stations for the International Latitude Service (ILS).

(3) Comparison of the observation methods.

Oct. 1898 12th General Conference of the Internationale Erdmessung in Stuttgart: Helmert and Albrecht submitted the report about the preparations for the ILS. Eight proposals were prepared by the Latitude Commission. The delegates adopted them with (6) modified.

\section{Start of the International Latitude Service}

1899 The International Latitude Service started as the first permanent worldwide scientific cooperation. Its Central Bureau charged with the programs and data reductions was installed at the Geodetic Institute of Potsdam under the responsibility of Albrecht. 


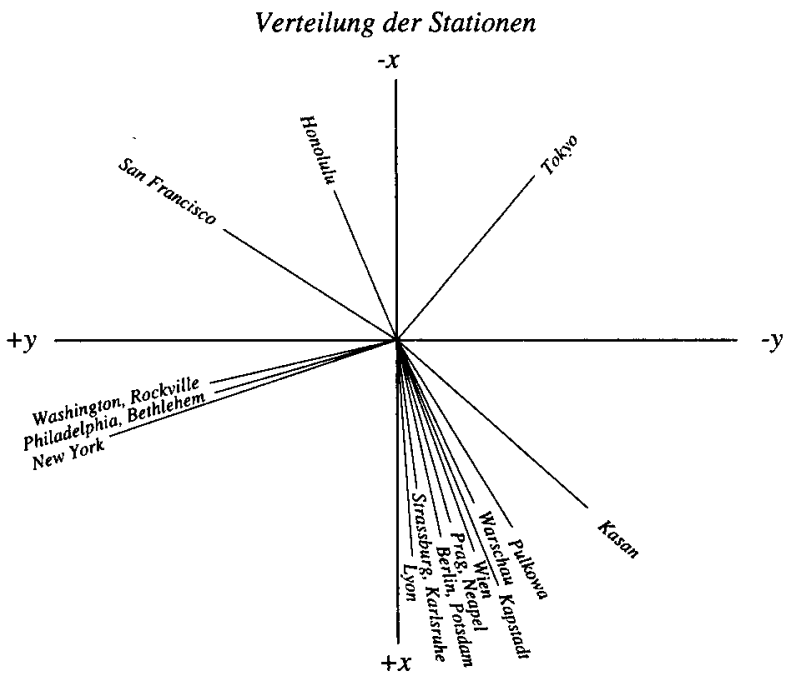

Bahn des Nordpoles der Erdachse

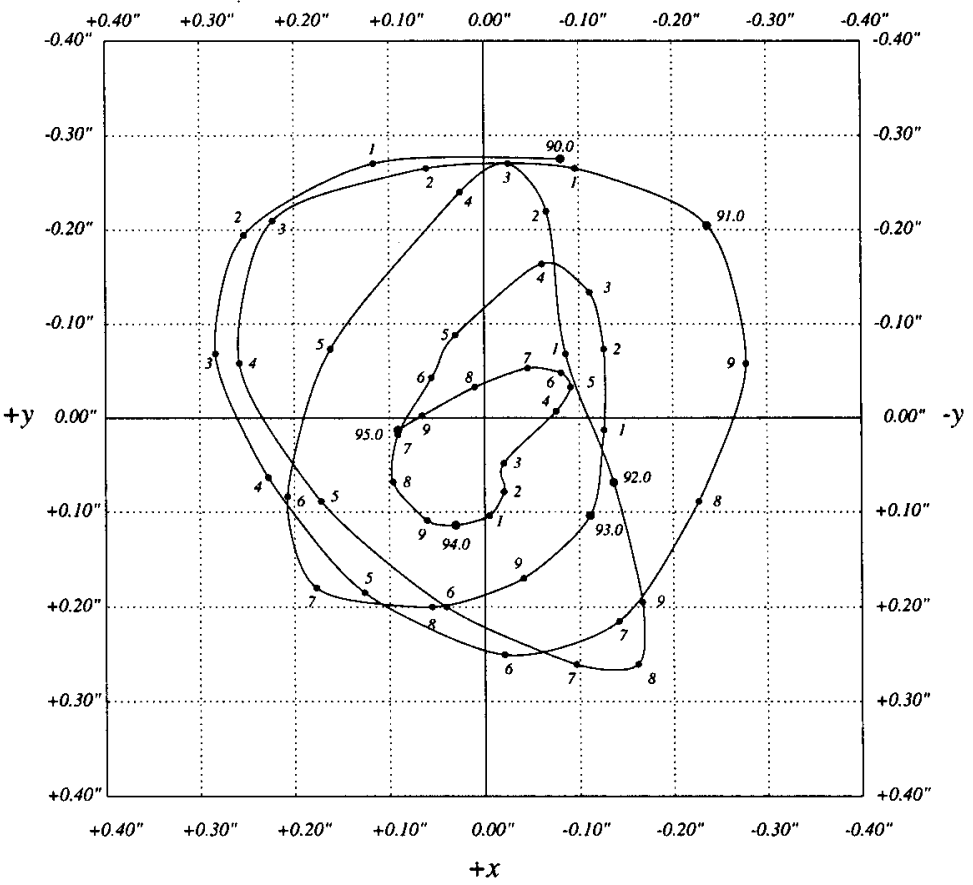

Figure 2. Polar motion from 1890.0 to 1895.0 derived from latitude observations at 20 independent stations (from Albrecht, 1898). Top: Distribution of the stations. Bottom: Motion of the northern pole of the Earth's axis given by values at 0.1 year intervals. 

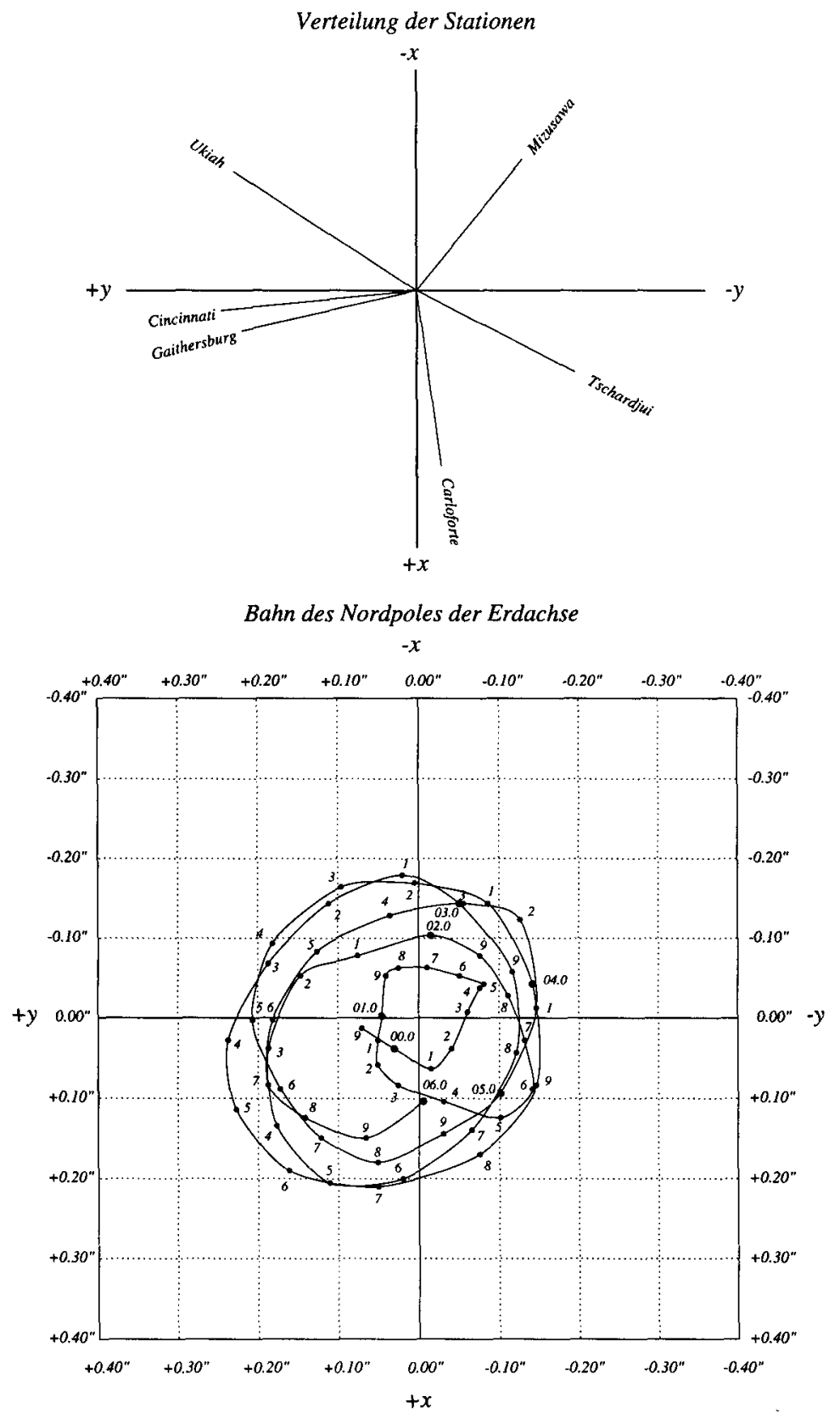

Figure 3. Polar motion from 1899.9 to 1906.0 derived from the latitude observations at the International Latitude stations (from Albrecht \& Wanach, 1909). Top: Distribution of the stations. Bottom: Motion of the northern pole of the Earth's axis given as in Figure 2. 
Sept. 1899 The latitude observations at the ILS stations on the latitude $+39^{\circ}$ 08 ' started.

1903 The results of the ILS from 1899 to 1902 (Vol. I) were published by Albrecht.

1909 The results of the ILS from 1899 to 1906 (Vol. III) were published by Albrecht \& Wanach; see Figure 3.

1915 Wanach became head of the ILS (until 1922).

1916 The results of the ILS from 1906 to 1912 (Vol. V) were published by Wanach.

1932 The results of the ILS from 1912.0 to 1922.7 were published by Wanach \& Mahnkopf.

For more details, see Höpfner (1999) and references therein.

\section{Appendix}

Friedrich Robert Helmert (1843-1917) Prof. Dr. phil., Dr. Ing. e. h.

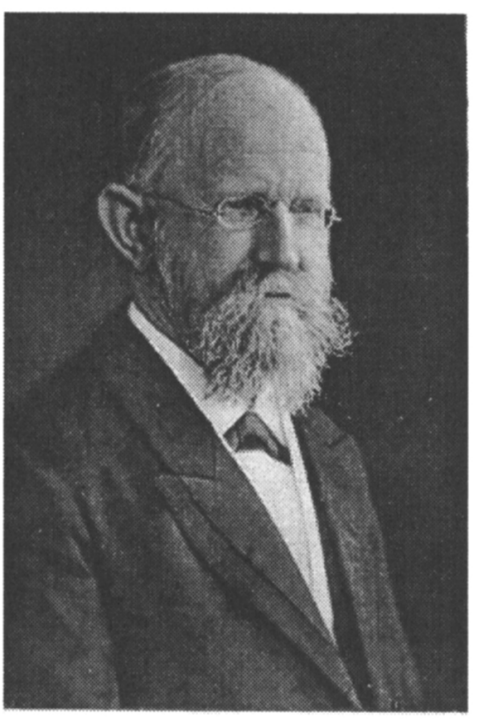

July 31, 1843 Born in Freiberg, Saxony (Sachsen)

1859-1863 Study of geodesy at the

Polytechnic College of Dresden

1863-1866 Assistant at the Saxon Arc

Measurement in Dresden

1866-1868 Study of mathematics, physics and astronomy at the University of Leipzig

May 12, 1868 Received his Dr. phil.

degree

Feb. 1, 1869 Observer at the

Observatory of Hamburg

Oct. 1, 1870 Teacher at the Technical College of Aachen

Dec. 21, 1872 Professor at the Technical

College

Jan. 1, $1886 \quad$ Provisional director of the Royal Prussian Geodetic Institute in Berlin

(from April 1892 on the Telegrafenberg of Potsdam)

Oct. 1886 Director of the Central Bureau of the Internationale

Erdmessung 
April 15, 1887 Professor for mathematical geodesy at the University of Berlin

April 22, 1887 Director of the Royal Prussian Geodetic Institute Jan. 31, 1900 Member of the Royal Prussian Academy of Sciences at Berlin Dec. 20, 1902 Honorary Doctoral Degree of the Technical College at Aachen Sept. 14, 1912 Great Gold Medal for Science on the jubilee of the Internationale Erdmessung June 15, 1917 Died in Potsdam

Carl Theodor Albrecht (1843-1915) Prof. Dr. phil., Dr.-Ing. h. c.

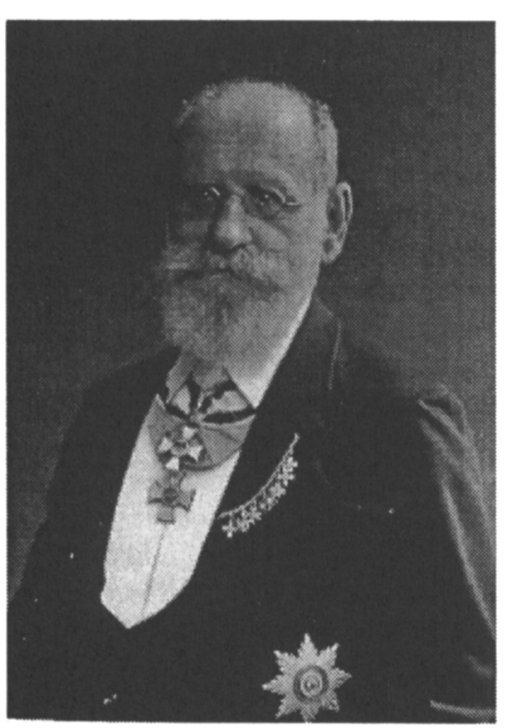

Aug. 30, 1843 Born in Dresden, Saxony (Sachsen)

$1860 \quad$ Study of geodesy at the

Polytechnic College of Dresden

1865-1868 Study of mathematics,

physics and astronomy at the University of

Berlin

May 1, 1866 Assistant at the Central

Bureau of the European Arc Measurement in Berlin

1868-1869 Study of astronomy at the University of Leipzig

1869 Received his Dr. phil.

degree

Jan. 1, 1870 Scientist at the Prussian

Geodetic Institute in Berlin

1873 Head of the Astronomical

Section

1875 Professor

1895 Head of the International

Latitude Service

1904 Corresponding Member of the Russian Geographical Society

1905 Associate of the Royal Astronomical Society

1907 Foreign Member of the Accademia dei Lincei

1910 Corresponding Member of the Academy of the Sciences at

Paris

1913 Honorary Doctoral Degree of the Technical College at

Stuttgart

Aug. 31, 1915 Died in Potsdam 
Bernhard Karl Wanach (1867-1928) Prof. Dr. phil. h. c.

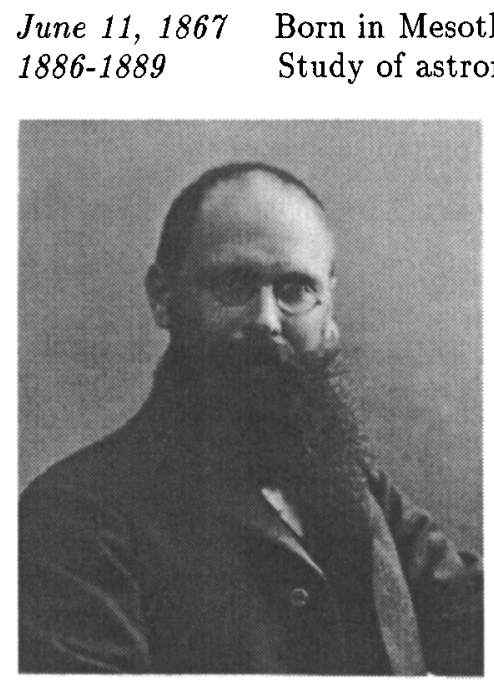

Born in Mesothen of Kurland

Study of astronomy at Dorpat; graduation in astronomy 1890-1891 Appointment as special astronomer at the Pulkovo Observatory 1892 Scientific assistant at the Observatory of Königsberg in Prussia 1893-1897 Scientific employee at the Observatory of Strasbourg in Elsaß 1897 Scientific employee of the time service at the Prussian Geodetic Institute of Potsdam Oct. $1902 \quad$ Scientific employee and observer (permanent scientist)
1906
Professor

1915

Head of the International

Latitude Service (until 1922)

1922

Head of the Astronomical

Section

1927

Honorary Doctoral Degree of the University at Königsberg

April 2, 1928 Died in Potsdam

\section{References}

Albrecht, Th., 1892, Resultate der Beobachtungsreihe in Honolulu betreffend die Veränderlichkeit der Polhöhe. C. B. Internat. Erdmessung. Berlin.

Albrecht, Th., 1898, Bericht über den Stand der Erforschung der Breitenvariation im December 1897. C. B. Internat. Erdmessung. Berlin.

Albrecht, Th. \& Wanach, B., 1909, Resultate des Internationalen Breitendienstes. Bd. III. Z. B. Internat. Erdmessung N. F. Veröff. Nr. 18. Berlin.

Euler, L., 1758, Du Mouvement de Rotation des Corps Solides autour d'un Axe Variable. Histoire de l'Académie Royale des Sciences et Belles Lettres. Berlin.

Höpfner, J., 1999, "On the contribution of the Geodetic Institute Potsdam to the International Latitude Service." GeoForschungsZentrum Potsdam. STR99/08.

Lagrange, J. L., 1788, Mécanique Analitique. Paris.

Poinsot, L., 1834, Théorie Nouvelle de la Rotation des Corps. L'Institut. J. Général des Sociétés et Travaux Scientifiques, 2. Paris. 